\title{
Bis(vinylenedithio)tetrathiafulvalene analogues of BEDT-TTF
}

\author{
Erdal Ertas ${ }^{*} 1, \S$, İlknur Demirtas ${ }^{1}$ and Turan Ozturk ${ }^{2,3}$
}

\author{
Review \\ Address: \\ ${ }^{1}$ TUBITAK Marmara Research Center, FI, P.O.Box 21, 41470 \\ Gebze-Kocaeli, Turkey, ${ }^{2}$ Istanbul Technical University, Science \\ Faculty, Chemistry Department, Organic Chemistry, 34469 Maslak, \\ Istanbul, Turkey and ${ }^{3}$ TUBITAK UME, Chemistry Group Laboratories, \\ P.O.Box 54, 41470 Gebze-Kocaeli, Turkey \\ Email: \\ Erdal Ertas* - erdal.ertas@tubitak.gov.tr \\ * Corresponding author \\ $\S$ Tel: +902626773209; Fax: +902626412309 \\ Keywords: \\ bis(ethylenedithio)tetrathiafulvalene; \\ bis(vinylenedithio)tetrathiafulvalene; tetrathiafulvalene
}

Open Access

Beilstein J. Org. Chem. 2015, 11, 403-415.

doi:10.3762/bjoc.11.46

Received: 28 January 2015

Accepted: 09 March 2015

Published: 27 March 2015

This article is part of the Thematic Series "Tetrathiafulvalene chemistry".

Guest Editor: P. J. Skabara

(c) 2015 Ertas et al; licensee Beilstein-Institut.

License and terms: see end of document.

\begin{abstract}
This review aims to give an overview of the current status of our research on the synthesis of $\pi$-electron donor bis(ethylenedithio)tetrathiafulvalene (BEDT-TTF, ET) analogues prepared from 1,8-diketones via a ring forming reaction. The new synthesized $\pi$-electron donors have vinyl moieties producing extended $\pi$-electron delocalization over the substituent phenyl rings at the peripheries.
\end{abstract}

\section{Introduction}

Tetrathiafulvalene (TTF, 1, Figure 1) was first synthesized in 1960s by Klingsberg's method [1]. Shortly after this, it was synthesized by other research groups and used as a donor molecule in 1970 [2]. Although, in 1972, 1 was demonstrated to be an organic material conductor in the form of its chloride salt [3]. The interest in the chemistry of $\mathbf{1}$ begun with the discovery of the salt of 1 with 7,7,8,8-tetracyanoquinodimethane (2, TTFTCNQ) in 1973 [4]. Since then, studies have been focused on the syntheses of donor TTF analogues and investigations of the physical properties of their charge-transfer (CT) salts with various acceptors for applications such as electrically conductive materials, super conductive materials, magnetic substances, electrochromic materials, electroluminescent materials, etc.
[5-16]. TTF-TCNQ, which is metallic under $54 \mathrm{~K}$ and known to be the first true one-dimensional synthetic metal, led to the production of superconducting salts based on TTF type donors containing a heteroatom such as sulfur, selenium, oxygen, etc. [17-20]. Among a large number of tetrathiafulvalene analogues, bis(ethyleneditiho)tetrathiafulvalene (BEDT-TTF, 3), also known as ET, has been the most studied and has had the largest number of radical cation salts of its CT materials investigated at very low temperature [12,21-24].

In order to improve the properties of TTF type materials, various methods have been applied, including extension of $\pi$-conjugation through double bonds [25-30] and fused aromatic 
<smiles>C1=CSC(=C2SC=CS2)S1</smiles>

1 TTF

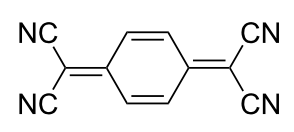

2 TCNQ<smiles>C1CSC2=C(S1)SC(=C1SC3=C(SCCS3)S1)S2</smiles>

3 BEDT-TTF or ET<smiles>[R]CSC1=C(SCC=[R])SC(=C2SC3=C(SC([R])=CS3)S2)S1</smiles>

4 BVDT-TTF

Figure 1: Chemical structure of the TTF analogues and TCNQ.

rings [31-34] and the construction of molecules having acceptor substituents [35-37]. Generally, all these modifications served to produce molecules with better conjugation and improved $\mathrm{S} \cdots \mathrm{S}$ intermolecular and $\mathrm{C}-\mathrm{H} \cdots$ anion interactions in determining the solid state properties [35-37]. Bis(vinylenedithio)tetrathiafulvalene (BVDT-TTF) $4(\mathrm{R}=\mathrm{Ph}$, 4- $\mathrm{CH}_{3} \mathrm{OC}_{6} \mathrm{H}_{4}, 4-\mathrm{BrC}_{6} \mathrm{H}_{4}, 4-\mathrm{CH}_{3} \mathrm{C}_{6} \mathrm{H}_{4}, 4-\mathrm{O}_{2} \mathrm{NC}_{6} \mathrm{H}_{4}$, 2-thienyl) is a BEDT-TTF analogue possessing $\pi$-bonds with aromatic groups on the outer rings (Figure 1) [26,38-41]. Since BEDTTTF has two ethylene units at the both ends of the molecule, it has a non-planar structure [42]. $\pi$-Extended molecules such as 4 with a vinylene group at the end of the BEDT-TTF unit have more planar structures $[41,43]$. Further, a tetrathiafulvalene with a fused aromatic heterocycle was synthesized as a $\pi$-extended donor molecule $[28,40]$. The most notable superconductivity was observed with the radical cation salts derived from the electron-donor molecule bis(ethylenedithio)tetrathiafulvalene $(\mathrm{BEDT}-\mathrm{TTF})$ as a $(\mathrm{BEDT}-\mathrm{TTF})_{2} \mathrm{Cu}\left[\mathrm{N}(\mathrm{CN})_{2}\right] \mathrm{Br}$ salt at $12.5 \mathrm{~K}$ (resistive onset) [24].

The tetrathiafulvalene (TTF) ring system is one of the most intensively studied redox-active organic molecules. It has two easily accessible oxidized states, $\mathrm{TTF}^{+}$and $\mathrm{TTF}^{2+}$ with potentials of $E_{1}{ }^{1 / 2}=+0.34$ and $E_{2}{ }^{1 / 2}=+0.78 \mathrm{~V}$, respectively, using $\mathrm{Ag} / \mathrm{AgCl}$ in acetonitrile, (Figure 2) $[5,6,44]$.

TTF analogues have been synthesized by coupling and without coupling methods $[45,46]$. Depending on the presence of electron-withdrawing groups on the TTF, they exhibit various oxidation potential ranges $[15,26]$. Recently, TTF and analogues have received widespread attention involving the development of new materials by using various anions to form different charge transfer salts. The physical and electronic properties of their solid states were investigated [13,25,47-49].
We attempt here to provide a summary of the synthesis of differently functionalized and extensively $\pi$-electron delocalized conjugated TTF core dithiin- and thiophene-fused donor molecules, obtained from 1,8-diketone ring closure reactions, and coupling reactions, published by our group.

\section{Review \\ BVDT-TTF analogues from 1,8-diketones}

Bis(vinylenedithio)tetrathiafulvalene (BVDT-TTF) $4(\mathrm{R}=\mathrm{Ph}$, 4- $\mathrm{CH}_{3} \mathrm{OC}_{6} \mathrm{H}_{4}, 4-\mathrm{BrC}_{6} \mathrm{H}_{4}, 4-\mathrm{CH}_{3} \mathrm{C}_{6} \mathrm{H}_{4}, 4-\mathrm{O}_{2} \mathrm{NC}_{6} \mathrm{H}_{4}$, 2-thienyl) is a fully unsaturated analogue of BEDT-TTF (ET) 3. It possesses a vinyl moiety at the peripheries in place of the ethylene group of ET. It can also be considered as a tetrathiafulvalene analogue having fused 1,4-dithiin rings as its peripheries. The synthesis was achieved through the reaction of a 1,8-diketone with Lawesson's reagent (LR) [50] or tetraphosphorus decasulfide $\left(\mathrm{P}_{4} \mathrm{~S}_{10}\right)$ [51] Although, in most cases, formation of 1,4dithiins is the only result, or the major one, a thiophene formation can also take place [46]. So far, eighteen BVDT-TTF analogues have been synthesized (Figure 3).

In 1996, we reported a convenient method of synthesizing fused 1,4-dithiin and thiophene ring systems, possessing functional groups such as $\mathrm{Ph} 4-\mathrm{MeOC}_{6} \mathrm{H}_{4}$ and $4-\mathrm{O}_{2} \mathrm{NC}_{6} \mathrm{H}_{4}$ (Scheme 1) [46]. The synthesis involved treatment of the diketone 6 , produced through the reaction of the readily available dianion $\mathbf{5}$ [52] with $\alpha$-haloketones, with Lawesson's reagent 15 to obtain [1,3-dithiolo[4,5-b][1,4]dithiin-2-thione 11, which is an analogue of half ET, as a major product, and the thiophene $\mathbf{1 3}$ as a minor product.

After employing different reaction conditions and an in depth study, we suggested that the reaction mechanism involves interaction of 6 with LR 15 (refluxing toluene) initially leading to<smiles>C1=CSC(=C2SC=CS2)S1</smiles>

1 TTF

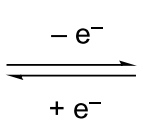

$+\mathrm{e}^{-}$

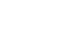<smiles></smiles>

TTF $^{+}$

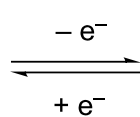

$+\mathrm{e}^{-}$<smiles></smiles>

$\mathrm{TTF}^{++}$

Figure 2: Oxidation states of TTF. 


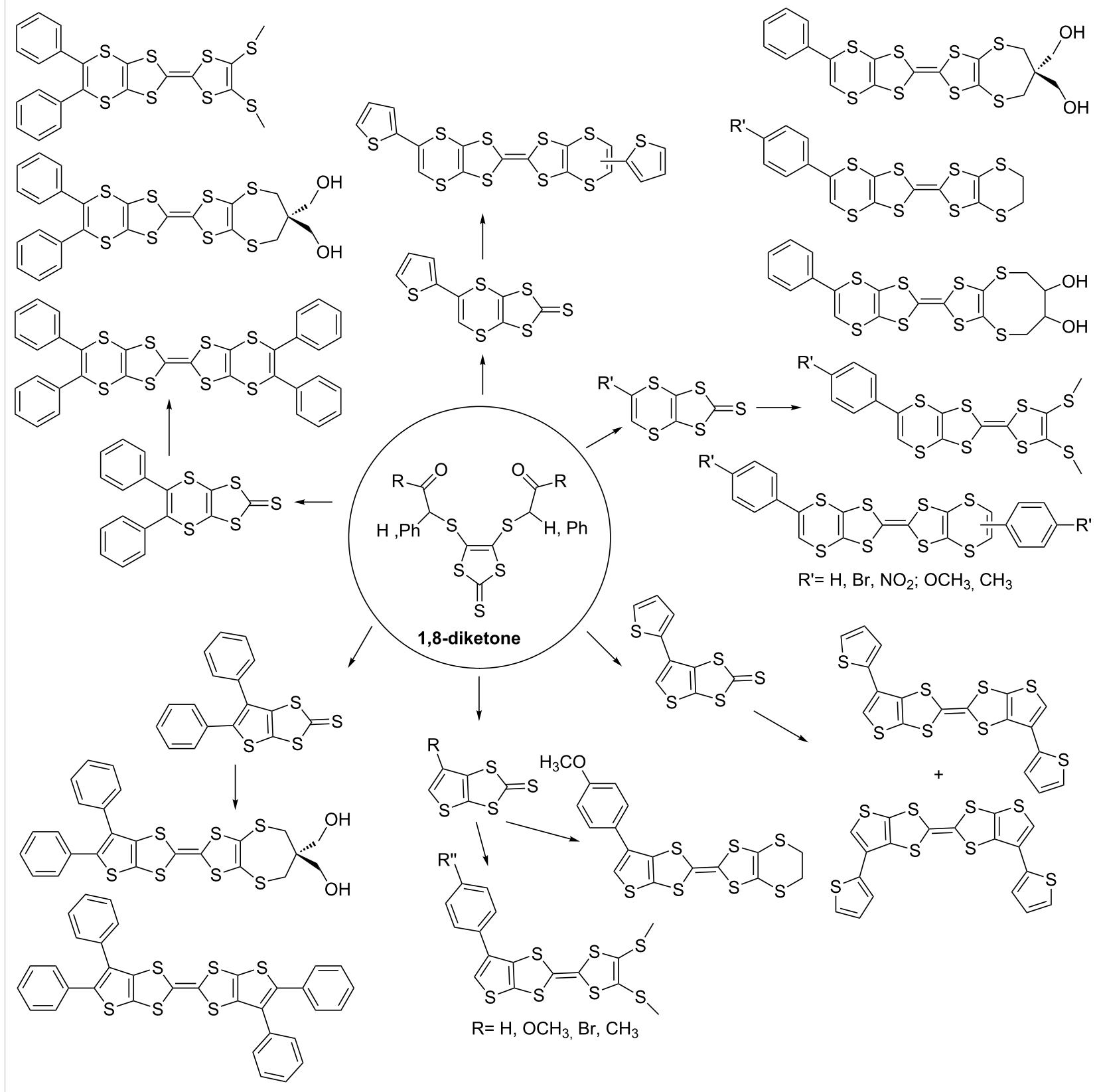

Figure 3: 1,4-Dithiin and thiophene fused TTF analogues from 1,8-diketone.

the formation of enethiols $\mathbf{8}$, a tautomer of 7 , then ninemembered ring $\mathbf{9}$, rearrangement of which produces $\mathbf{1 0}$. Lastly, the reaction of $\mathbf{1 0}$ with fragment $\mathbf{1 4}$ of LR would give $\mathbf{1 1}$ as a major product (Scheme 1). Rearrangement of the 1,4-dithiin unit of 11 would produce $\mathbf{1 3}$ as a minor product through the intermediate 12 by the loss of elemental sulfur. The reaction of a series of 1,8-diketones with LR 15 or $\mathrm{P}_{4} \mathrm{~S}_{10}$ was further explored in 2003 [53]. With both reactants, 1,4-dithiin 11 was obtained as a major and thiophene $\mathbf{1 3}$ as a minor product along with the side products 16-19 (Scheme 2).

Depending on the electron-releasing or electron-withdrawing nature of the groups on $\mathbf{6}$, the yields for $\mathbf{1 1}$ and 13, with LR varied between $35-52 \%$ and from not detected (n.d.) to $18 \%$, 
<smiles>[R]C(=O)CSc1sc(=S)sc1SCC([Y])=S</smiles>

$\mathrm{R}=\mathrm{Ph}, 4-\mathrm{O}_{2} \mathrm{NC}_{6} \mathrm{H}_{4}, 4-\mathrm{MeOC}_{6} \mathrm{H}_{4}$<smiles>[R]c1csc2sc(=S)sc12</smiles>

13

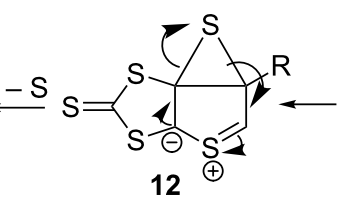

12<smiles>[R]/C(S)=C/Sc1sc(=S)sc1S/C=C(/[R])S</smiles><smiles>[AsH2][AsH2]</smiles>

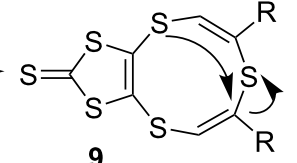

9<smiles></smiles>

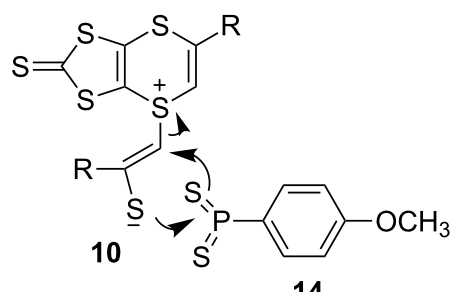

14

Scheme 1: Reaction mechanism of fused 1,4-dithiin and thiophene ring systems.

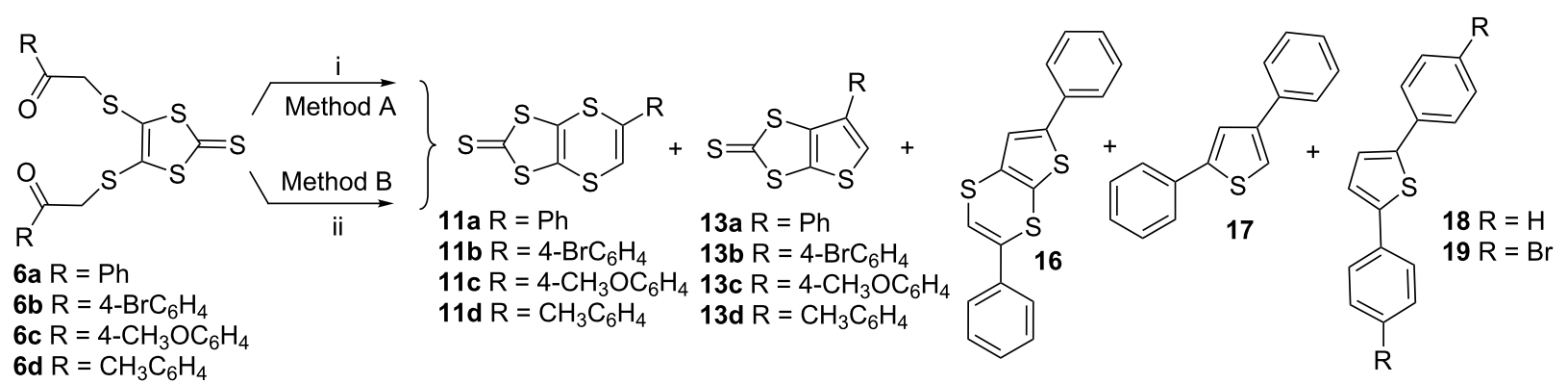

Scheme 2: Reaction conditions (i) LR, toluene, reflux, overnight; (ii) $\mathrm{P}_{4} \mathrm{~S}_{10}$, toluene, reflux, $3 \mathrm{~h}$.

respectively, $\mathrm{P}_{4} \mathrm{~S}_{10}$ gave yields for $\mathbf{1 1}$ and $\mathbf{1 3}$ from 5 to $49 \%$ and n.d. to $27 \%$, respectively. Both of the reagents produced the dithiin as a major product. Compound 13d, with a thiophene ring, was not obtained with either of the two reagents (Table 1).
A possible reaction mechanism for the formation of 16-19 was suggested to involve the intermediate 10 (Scheme 3) [46-53]. A detailed semi-empirical PM3 calculation indicated that the formation of the intermediate $\mathbf{1 0}$ is an endothermic process with

\begin{tabular}{|c|c|c|c|c|}
\hline \multirow{2}{*}{$\begin{array}{l}\text { Starting } \\
\text { material }\end{array}$} & \multicolumn{2}{|c|}{ LR } & \multicolumn{2}{|c|}{$\mathrm{P}_{4} \mathrm{~S}_{10}$} \\
\hline & dithiin & thiophene & dithiin & thiophene \\
\hline $6 a$ & $11 \mathrm{a}(40 \%)$ & $\begin{array}{l}13 a(17 \%) \\
16(15 \%) \\
17(<1 \%) \\
18(9 \%)\end{array}$ & 11a (49\%) & $\begin{array}{l}13 a \text { (n.d.) } \\
17 \text { (8\%) } \\
18 \text { (n.d.) }\end{array}$ \\
\hline $6 b$ & $11 b(35 \%)$ & 13b (18\%) & $11 b(40 \%)$ & $\begin{array}{l}13 \mathrm{~b}(2 \%) \\
19(10 \%)\end{array}$ \\
\hline $6 c$ & 11c $(45 \%)$ & $13 c(15 \%)$ & $11 \mathrm{c}(30 \%)$ & $13 c(27 \%)$ \\
\hline $6 d$ & $11 d(52 \%)$ & 13d (n.d.) & $11 d(5 \%)$ & 13d (n.d.) \\
\hline
\end{tabular}

n.d.: not detected. 


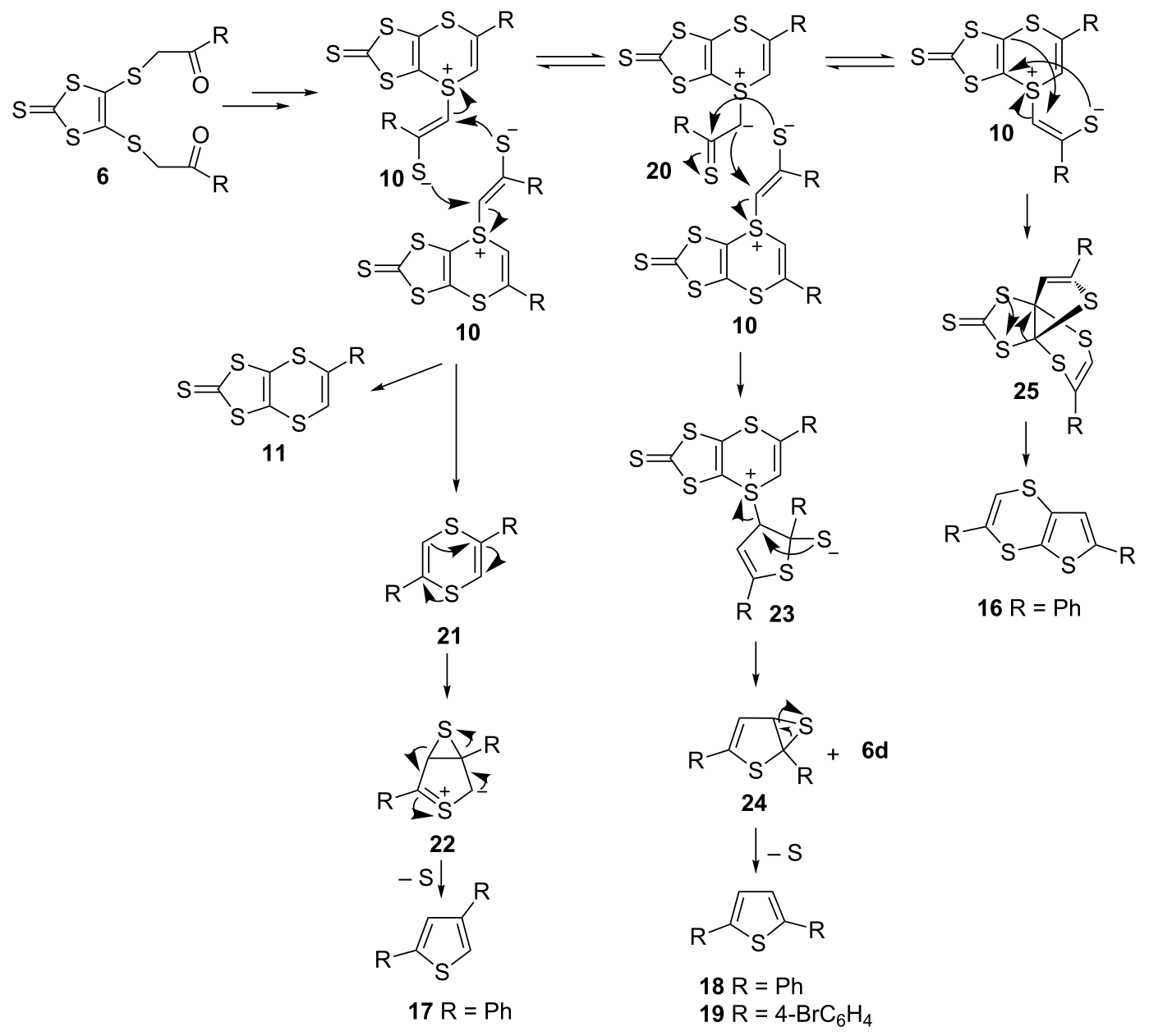

Scheme 3: Proposed mechanism for side products.

$\Delta H_{\mathrm{rxn}}=29.435 \mathrm{kcal} / \mathrm{mol}$. The reaction of the intermediate $\mathbf{1 0}$ with itself could produce the 1,4-dithiin ring $\mathbf{1 1}$ and the side product thiophene $\mathbf{1 7}$ through the intermediates $\mathbf{2 1}$ and $\mathbf{2 2}$ by removal of elemental sulfur (Scheme 3 ). The other side products 18 and 19 were possibly formed from the reaction of $\mathbf{1 0}$ with $\mathbf{2 0}$, leading to formation of $\mathbf{2 3}$ and $\mathbf{2 4}$, rearrangement of which would then produce 18 and 19. Moreover, rearrangement of $\mathbf{1 0}$ via $\mathbf{2 5}$ would result in the formation of $\mathbf{1 6}$. The structures of the side products $\mathbf{1 6}-\mathbf{1 9}$ can be taken as evidence for the proposed reaction mechanism.

The thione sulfur atoms of $11 \mathbf{a}-\mathbf{d}$ and $\mathbf{1 3 a}-\mathbf{c}$ were converted into their corresponding oxo forms $\mathbf{2 6 a}-\mathbf{d}$ and $\mathbf{2 7 a}-\mathbf{c}$, respectively, using mercury acetate (Scheme 4) [46,53,54]. These were then subjected to cross coupling reactions. While the cross couplings of 26a-d with $\mathbf{2 8}$ and $\mathbf{3 1}$ [53] led to the formation of 29a-d and 32a-d, respectively, along with the self coupling products 4,30 and 3 , coupling of $27 \mathbf{a}-\mathbf{c}$ with 28 gave $33 \mathbf{a}-\mathbf{c}$ and the self coupling products $\mathbf{3 4 a}-\mathbf{c}$ and $\mathbf{3 0}$. The cross coupled product $\mathbf{3 5}$ from $\mathbf{2 7} \mathbf{c}$ and $\mathbf{3 1}$ was obtained in a similar manner.

The redox properties of the donor molecules $29 \mathbf{a}-\mathbf{d}, \mathbf{3 2} \mathbf{a}-\mathbf{d}$, 33a-c and ET 3 were studied by cyclic voltammetry in solution in acetonitrile, containing $\mathrm{NaClO}_{4}$ and dichloromethane, containing tetrabutylammonium tetrafluoroborate $\left(\mathrm{TBABF}_{4}\right)$ (Table 2 and Table 3). Measurements were performed under a nitrogen atmosphere at room temperature using $\mathrm{Pt}$ as working and counter electrodes and $\mathrm{Ag} / \mathrm{AgCl}$ reference electrode. The oxidation potentials of the coupled products were compared with ET 3.

The measurements indicated that as the first oxidation potential of ET was higher than the first oxidation potential of 29a, 29c and $29 d$, the oxidation potential of $29 b$ was equal to that of 


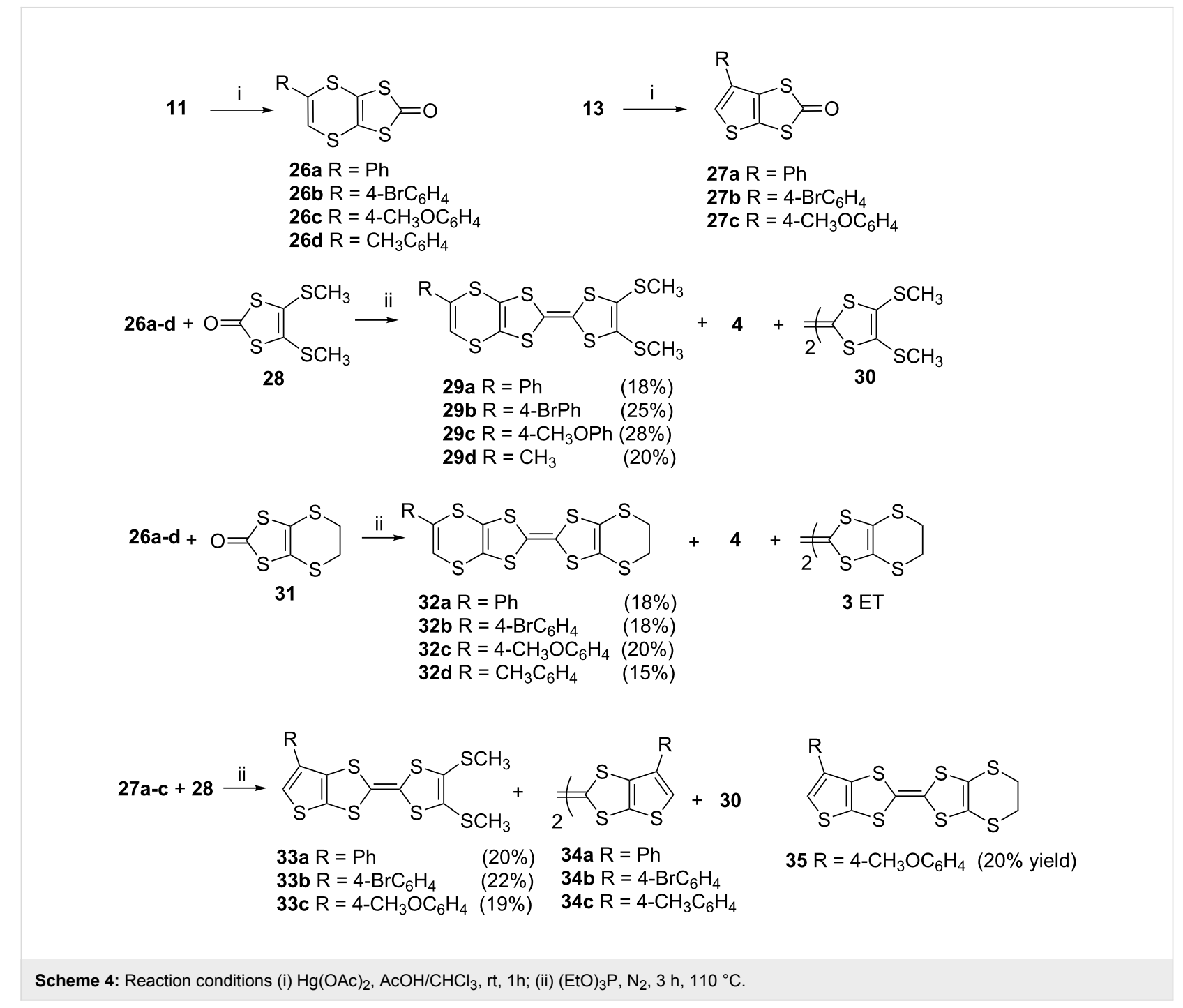

Table 2: Redox potential of 29 and ET 3. in $1 \mathrm{mM} \mathrm{MeCN}$ solution, $\mathrm{NaClO}_{4}(0.1 \mathrm{M})$ vs Ag/AgCl, $100 \mathrm{mVs}^{-1}$.

\begin{tabular}{cccc} 
Donor & $E^{1}{ }_{\text {ox }}(\mathrm{V})$ & $E^{2}{ }_{\text {ox }}(\mathrm{V})$ & $\Delta E_{\text {ox }}(\mathrm{V})$ \\
\hline 29a & 0.49 & 0.63 & 0.14 \\
29b & 0.50 & 0.63 & 0.13 \\
29c & 0.47 & 0.72 & 0.25 \\
29d & 0.42 & 0.66 & 0.24 \\
3 ET & 0.50 & 0.77 & 0.27
\end{tabular}

ET 3 and the second oxidation potentials of $\mathbf{2 9 a}-\mathbf{d}$ were found to be lower than for ET. On the other hand, the first and second oxidation potentials of the donors 33a-c were slightly higher than the oxidation potentials of ET. The oxidation potentials of the donor molecules 32a-d were higher than the ET 3 oxidation potential.
Table 3: Redox potential of 32a-d and 33a-c. and ET 3 in $1 \mathrm{mM}$ $\mathrm{CH}_{2} \mathrm{Cl}_{2}$ solution, $\mathrm{TBABF}_{4}(0.1 \mathrm{M})$ vs $\mathrm{Ag} / \mathrm{AgCl}, 115 \mathrm{mVs}^{-1}$.

\begin{tabular}{cccc} 
Donor & $E_{\text {ox }}^{1}(\mathrm{~V})$ & $E_{\text {ox }}^{2}(\mathrm{~V})$ & $\Delta E_{\text {ox }}(\mathrm{V})$ \\
\hline 32a & 0.66 & 0.96 & 0.30 \\
32b & 0.60 & 0.95 & 0.35 \\
32c & 0.68 & 1.00 & 0.32 \\
32d & 0.64 & 0.99 & 0.24 \\
33a & 0.59 & 0.86 & 0.27 \\
33b & 0.51 & 0.83 & 0.32 \\
33c & 0.62 & 0.94 & 0.32 \\
3 ET & 0.51 & 0.85 & 0.34
\end{tabular}

A BEDT-TTF analogue containing phenyl-1,4-dithiin and 2,3dihydroxybutane-1,4-dithio at the periphery, 43 , was reported as a new highly functionalized donor molecule (Scheme 5) [54]. 

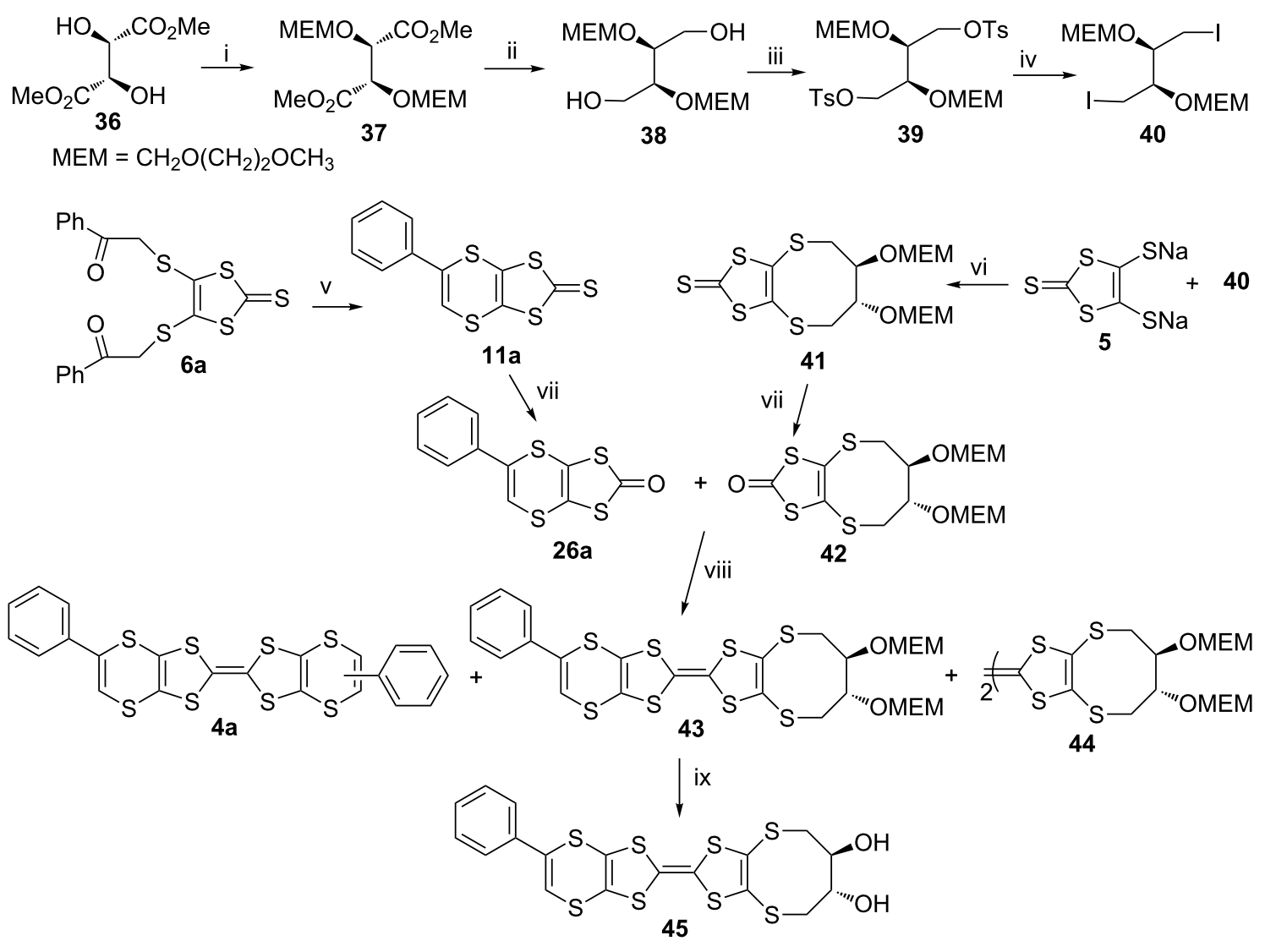

Scheme 5: Reaction conditions (i) $\mathrm{Pr}_{2} \mathrm{NEt}, \mathrm{MEMCl}, \mathrm{THF}, \mathrm{rt}, 12 \mathrm{~h}$; (ii) LiAlH 4 , dry ether, rt, $24 \mathrm{~h}$; (iii) tosyl chloride, dry pyridine, $0{ }^{\circ} \mathrm{C}, 4 \mathrm{~h}$; (iv) $\mathrm{KI}$, dry acetone, $\mathrm{N}_{2}$, reflux, overnight; (v) dry THF, $75^{\circ} \mathrm{C}, \mathrm{N}_{2}, 48 \mathrm{~h}$; (vi) $\mathrm{P}_{4} \mathrm{~S}_{10}$, toluene, reflux, $3 \mathrm{~h}$; (vii) $\mathrm{Hg}(\mathrm{OAc})_{2}, \mathrm{AcOH} \mathrm{CHCl} 3, \mathrm{rt}, 2 \mathrm{~h}$; (viii) neat (EtO) ${ }_{3} \mathrm{P}, \mathrm{N}_{2}$, $3 \mathrm{~h}$; (ix) sample in $\mathrm{THF}$ at $0^{\circ} \mathrm{C}$, add $20 \% \mathrm{HCl}$, then rt., overnight.

The reaction of diketone 6a, with LR 15 in refluxing toluene for $3 \mathrm{~h}$ gave the dithiin 11a, which was converted into the oxo form 26a with mercuric acetate in $\mathrm{CHCl}_{3} /$ glacial acetic acid at room temperature in $\mathbf{2}$ h. Synthesis of $\mathbf{4 1}$ was completed in five steps, starting from dimethyl L-tartrate 36, the hydroxy groups of which were protected by reaction with methoxyethoxymethyl chloride (MEMCl) and then the ester groups of $\mathbf{3 7}$ were reduced to alcohols with $\mathrm{LiAlH}_{4}$ to obtain the diol 38. This was converted into 39 through tosylation of the hydroxy groups with tosyl chloride and then conversion into iodides $\mathbf{4 0}$ using potassium iodide. Treatment of $\mathbf{4 0}$ with the dianionic salt $\mathbf{5}$ in dry acetone at room temperature produced 41 [55], which was transformed into the corresponding oxo form $\mathbf{4 2}$ by applying the same reaction conditions used to obtain 26a. Coupling of 26a with 42 was performed in neat triethyl phosphite at $130{ }^{\circ} \mathrm{C}$ for 3 $\mathrm{h}$ under a nitrogen atmosphere, which gave a mixture of cross coupled 43 and self coupled products $4 a$ and 44 . In order to remove the MEM protecting group, $\mathbf{4 3}$ was stirred in $20 \% \mathrm{HCl}$ at room temperature for 2 days, which yielded the ET analogue $\mathbf{4 5}$, having two hydroxy groups.
In 2000, syntheses of 5,6-diphenyl[1,3]dithiolo[4,5b] [1,4]dithiin-2-thione $\mathbf{4 8}$ and its coupling product $\mathbf{5 2}$, which is a fully unsaturated analogue of BEDT-TTF, were achieved. The 1,8-diketone 47 was easily obtained from the reaction of the dianion 5 ( 1 equiv) and desyl chloride 46 (2 equiv) in dry ethanol at room temperature for $3 \mathrm{~h}$ in $90 \%$ yield (Scheme 6) [40].

The ring closure reaction of $\mathbf{4 7}$ was performed initially using LR, which produced only the thiophene 50, similar to the result obtained by another research group [28]. Next, the reaction was conducted with $\mathrm{P}_{4} \mathrm{~S}_{10}$, which gave benzylphenyldithiole 49 and the thiophene $\mathbf{5 0}$ in 25 and $30 \%$ yields. Considering that the reaction could take place through a radical mechanism, it was repeated in the dark using $\mathrm{P}_{4} \mathrm{~S}_{10}$. After $3 \mathrm{~h}$ of reflux in toluene, the dithiin 48 was successfully obtained in $65 \%$ along with a trace of benzylphenyldithiole $\mathbf{4 9}$ and the thiophene $\mathbf{5 0}$ in $20 \%$ yields. The fully unsaturated tetraphenyl analogue $\mathbf{5 2}$ of ET was obtained in $90 \%$ yield by a coupling reaction of $\mathbf{5 1}$, which was obtained by converting the thione group of $\mathbf{4 8}$ to its corres- 


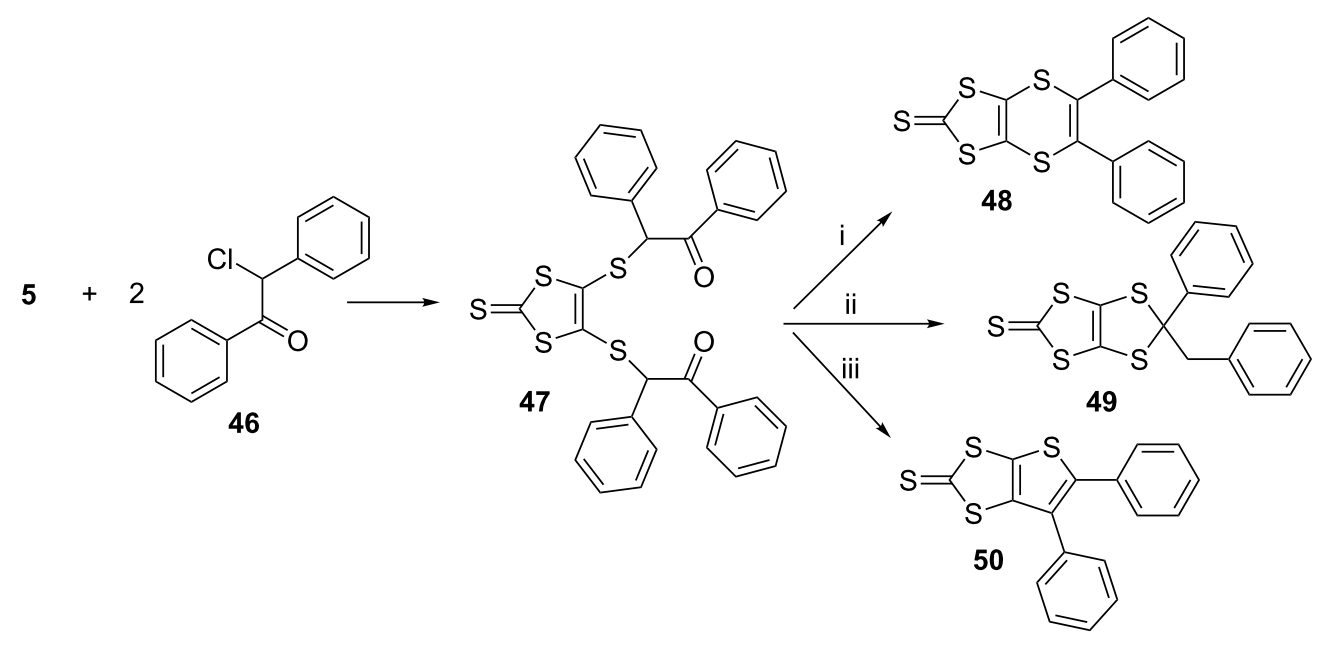

Scheme 6: Reagents and conditions (i) $\mathrm{P}_{4} \mathrm{~S}_{10}$, toluene, reflux, dark, $3 \mathrm{~h}$; (ii) $\mathrm{P}_{4} \mathrm{~S}_{10}$, toluene, reflux, $3 \mathrm{~h}$; (iii) LR, toluene, reflux, overnight.

ponding oxo form in $85 \%$ yield, in hot triethyl phosphite, dichloromethane at room temperature to investigate the optical yielding $\mathbf{5 2}$ in $90 \%$ yield (Scheme 7). constant and optical band gap of the complex (Scheme 8) [56]. A solution of the salt was evaporated on a quartz substrate until

A charge transfer salt $\mathbf{5 4}$ of $\mathbf{5 2}$ was prepared with the acceptor $\approx 110 \mathrm{~nm}$ thickness of the film was obtained. The film was 2,3-dichloro-5,6-dicyano-p-benzoquinone (DDQ) 53 (1:1) in annealed at $25,55,85,115$ and finally at $145{ }^{\circ} \mathrm{C}$ for $30 \mathrm{~min}$.<smiles>CC(C)COC(=O)C(C)(C)C</smiles>

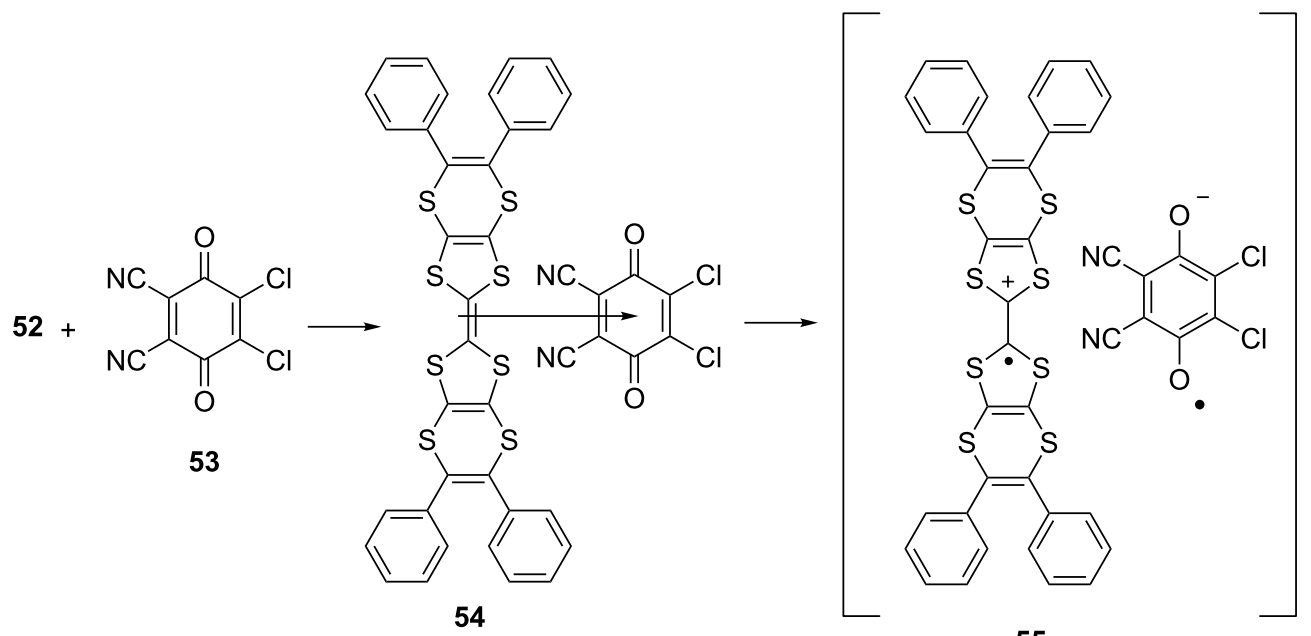


Electronic transitions of the complex 54, i.e. $\mathrm{n}-\pi^{*}$ and $\pi-\pi^{*}$ transitions, led to the formation of radical ion pairs $\mathbf{5 5}$. The refractive index dispersion and optical constant of the annealed film were examined for each temperature. The absorbance, refractive index, reflectance and transmittance values of the material were found to be between $0.16-0.32,2.3-2.7,16-20 \%$ and $46-66 \%$, respectively at $400-800 \mathrm{~nm}$ wavelength range which clearly indicated that the refractive index, absorbance and reflectance of the complex decreased while transmittance increased with increased annealing temperature.

Our easy synthesis of dithiin-containing compounds led to the production of various BEDT-TTF analogues, comprising monophenyldithiin, diphenyldithiin, diphenylthiophene and diols [40,46,53]. While coupling of $\mathbf{2 8}$ with $\mathbf{5 1}$ smoothly gave the corresponding ET analogue 56, its reaction with $\mathbf{5 7}$ did not produce any result (Scheme 9) [57]. This could be due to the reaction of the benzylphenyldithiole moiety with triethyl phosphite.

Analogues of ET, having dithiin and thiophene rings along with hydroxy groups were synthesized to provide the possibility of intramolecular hydrogen bonding through the hydroxy groups [57]. The half ET analogue $\mathbf{6 1}$ was obtained from the reactions of either the dianion $\mathbf{5}$ or the zinc-complex $\mathbf{5 9}$ with 2-bis(bromomethyl)propane-1,3-diol (60, Scheme 10). As the hydroxy groups could lead to side products during the coupling reaction, performed using triethyl phosphite, and the reaction for conversion of the thione group to a keto group with mercury acetate and acetic acid, they were protected by reaction with methoxyethoxymethylchloride $\left(\mathrm{CH}_{3} \mathrm{OCH}_{2} \mathrm{CH}_{2} \mathrm{OCH}_{2} \mathrm{Cl}\right.$, $\mathrm{MEMCl}$ ) to obtain $\mathbf{6 2}$. The thione group of this compound, was then converted into a keto group to give 63. Its reaction with 26a-c in triethyl phosphite led to the formation of crosscoupled product $64 \mathbf{a}-\mathbf{c}$, along with the self coupled one. Following the same procedure, the half ET analogue $\mathbf{6 5}$, possessing a fused diphenylthiophene ring was coupled with $\mathbf{6 3}$ to produce 66, along with self coupled products like $\mathbf{6 7}$. Removal of the MEM groups of both $\mathbf{6 4}$ and $\mathbf{6 6}$ in dilute $\mathrm{HCl}$ / THF mixture resulted in the formation of the target analogues 68a-c and 69, having two hydroxy groups. Coupling of the dithiinone 51 with 63 gave 70 and its hydrolysis yielded the ET analogue 71, possessing diphenyldithiin and two hydroxy groups. Following the same strategy, an ET analogue 72, having half ET and two hydroxy groups was synthesized to compare the oxidation and reduction potentials of the analogues. The yields of the resultant products are given in Table 4 .

\begin{tabular}{|cccc}
\hline Table 4: Yields of the products 64, 65, 68-71. & \\
\hline & & & \\
Product & Yield (\%) & Diol & Yield (\%) \\
\hline $\mathbf{7 0}$ & 30 & $\mathbf{7 1}$ & 75 \\
$\mathbf{6 5}$ & 30 & $\mathbf{6 9}$ & 75 \\
$\mathbf{6 4 a}$ & 27 & $\mathbf{6 8 a}$ & 43 \\
$\mathbf{6 4 b}$ & 29 & $\mathbf{6 8 b}$ & 35 \\
$\mathbf{6 4 c}$ & 40 & $\mathbf{6 8 c}$ & 34 \\
\hline
\end{tabular}

The oxidation and reduction properties of the diphenyl analogues 56, 69 and 71 and monophenyl analogues 68a-c, 31a and 29a were investigated and compared by cyclic voltammetry (CV) (Table 5) with ET 3 and its fully unsaturated tetraphenyl analogue 52. The CV measurement of the donors was performed in $0.1 \mathrm{M} \mathrm{NaClO}_{4} / \mathrm{ACN}$ with a scan rate of $100 \mathrm{mVS}^{-1}$ at room temperature, using Pt working and $\mathrm{Ag} / \mathrm{Ag}^{+}$ reference electrodes. The spectroelectrochemical studies were carried out in $\mathrm{CH}_{2} \mathrm{Cl}_{2}$ containing $0.1 \mathrm{M} \mathrm{TBABF}_{4}$ at room temperature.

The CV studies indicated that while the fully unsaturated $\mathbf{5 2}$ and diphenylthiophenedimethylthio 67 had the highest

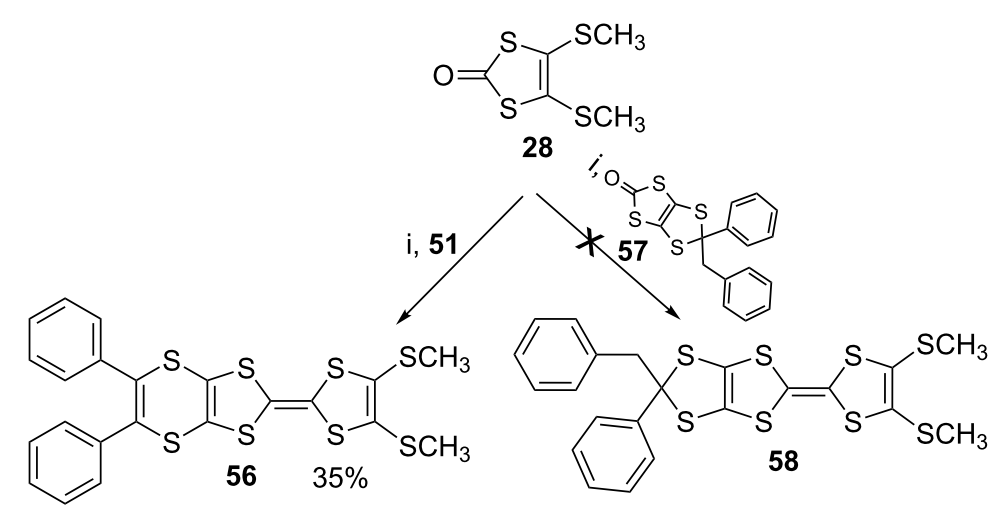

Scheme 9: Reaction conditions (i) $(\mathrm{EtO})_{3} \mathrm{P}, 110^{\circ} \mathrm{C}, \mathrm{N}_{2}, 2 \mathrm{~h}$. 


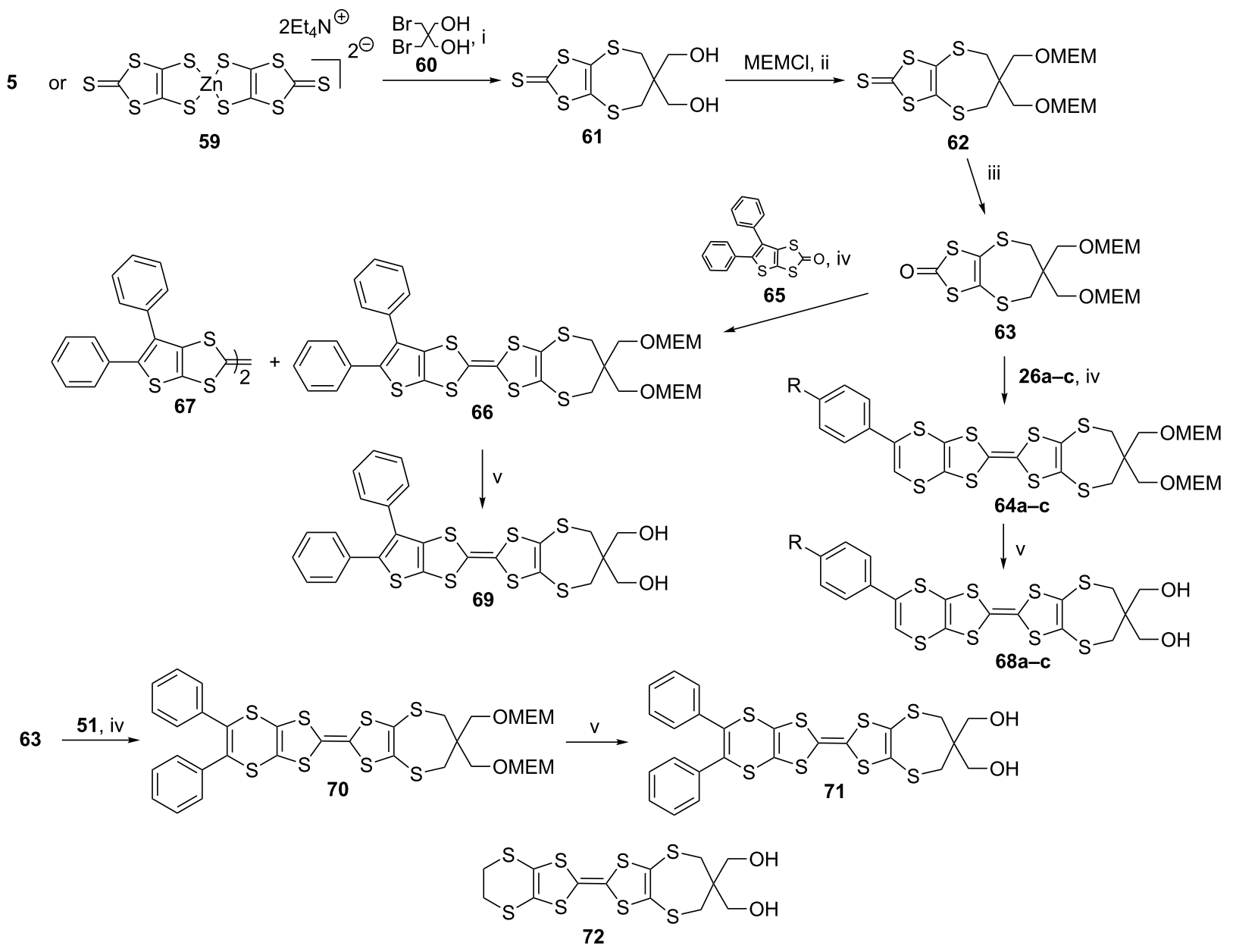

Scheme 10: Reaction conditions (i) $\mathrm{EtOH}$, reflux, overnight; (ii) diisopropylethylamine in $\mathrm{CH}_{2} \mathrm{Cl}_{2}$, room temperature, overnight; (iii) $(\mathrm{AcO}){ }_{2} \mathrm{Hg} / \mathrm{AcOH}$, $\mathrm{CHCl}_{3}$, rt, 3h; iv) (EtO) ${ }_{3} \mathrm{P}, 110^{\circ} \mathrm{C}, \mathrm{N}_{2}, 2 \mathrm{~h}$; (v) sample in $\mathrm{THF}$ at $0^{\circ} \mathrm{C}$, add $20 \% \mathrm{HCl}$, then rt, overnight.

Table 5: Redox potential of ET 3 and its analogues, ACN solution of $0.1 \mathrm{M} \mathrm{NaClO}_{4}$

\begin{tabular}{cccc} 
& \multicolumn{3}{c}{ Oxidation potential $(\mathrm{V})$} \\
\cline { 2 - 4 } Sample & $E^{1}$ OX $(\mathrm{V})$ & $E^{2}$ OX $(\mathrm{V})$ & $\Delta E(\mathrm{~V})$ \\
$\mathbf{5 2}$ & 0.72 & 1.03 & 0.31 \\
$\mathbf{6 6}$ & 0.44 & 0.70 & 0.26 \\
$\mathbf{7 1}$ & 0.60 & 0.84 & 0.24 \\
$\mathbf{6 9}$ & 0.41 & 0.63 & 0.22 \\
$\mathbf{5 6}$ & 0.57 & 0.80 & 0.23 \\
$\mathbf{6 8 a}$ & 0.36 & 0.59 & 0.23 \\
$\mathbf{6 8 b}$ & 0.49 & 0.74 & 0.25 \\
$\mathbf{6 8 c}$ & 0.50 & 0.76 & 0.26 \\
$\mathbf{6 7}$ & 0.42 & 0.70 & 0.28 \\
$\mathbf{3 1 a}$ & 0.72 & 1.06 & 0.34 \\
$\mathbf{7 2}$ & 0.49 & 0.63 & 0.14 \\
$\mathbf{2 9 a}$ & 0.42 & 0.70 & 0.28 \\
$\mathbf{3 E T}$ & 0.66 & 0.96 & 0.30 \\
& 0.46 & 0.71 & 0.25 \\
& & &
\end{tabular}

oxidation potentials, diphenyldithiindimethylthio $\mathbf{5 6}$ displayed the lowest oxidation potential and combination of dithiin and diol groups led to oxidation potentials comparable with ET 3.

BEDT-TTF analogues possessing thiophene substituted 1,4dithiin and thiophene rings were reported in 2013 [58]. Their syntheses began with our standard synthesis of a 1,8-diketone 74 having a thiophene in place of a benzenoid aromatic group (Scheme 11). Reaction of the zinc-complex 59 with four mol equivalents of $\alpha$-bromoketone $\mathbf{7 2}$ gave the diketone $\mathbf{7 4}$ in $80 \%$ yield, subsequent ring closure of which with $\mathrm{P}_{4} \mathrm{~S}_{10}$ in acidic and basic conditions produced 1,4-dithiin 75 (75\%) and thiophene 76 (57\%) rings, respectively. They were then converted into their corresponding oxo forms 77 (65\%) and 78 (77\%), respectively, with mercury acetate and subjected to the coupling reaction with triethyl phosphite to produce the ET analogues having 1,4-dithiin rings 79 (80\%) and thiophene rings 80 and 81 (75\%) as inseparable isomers. 

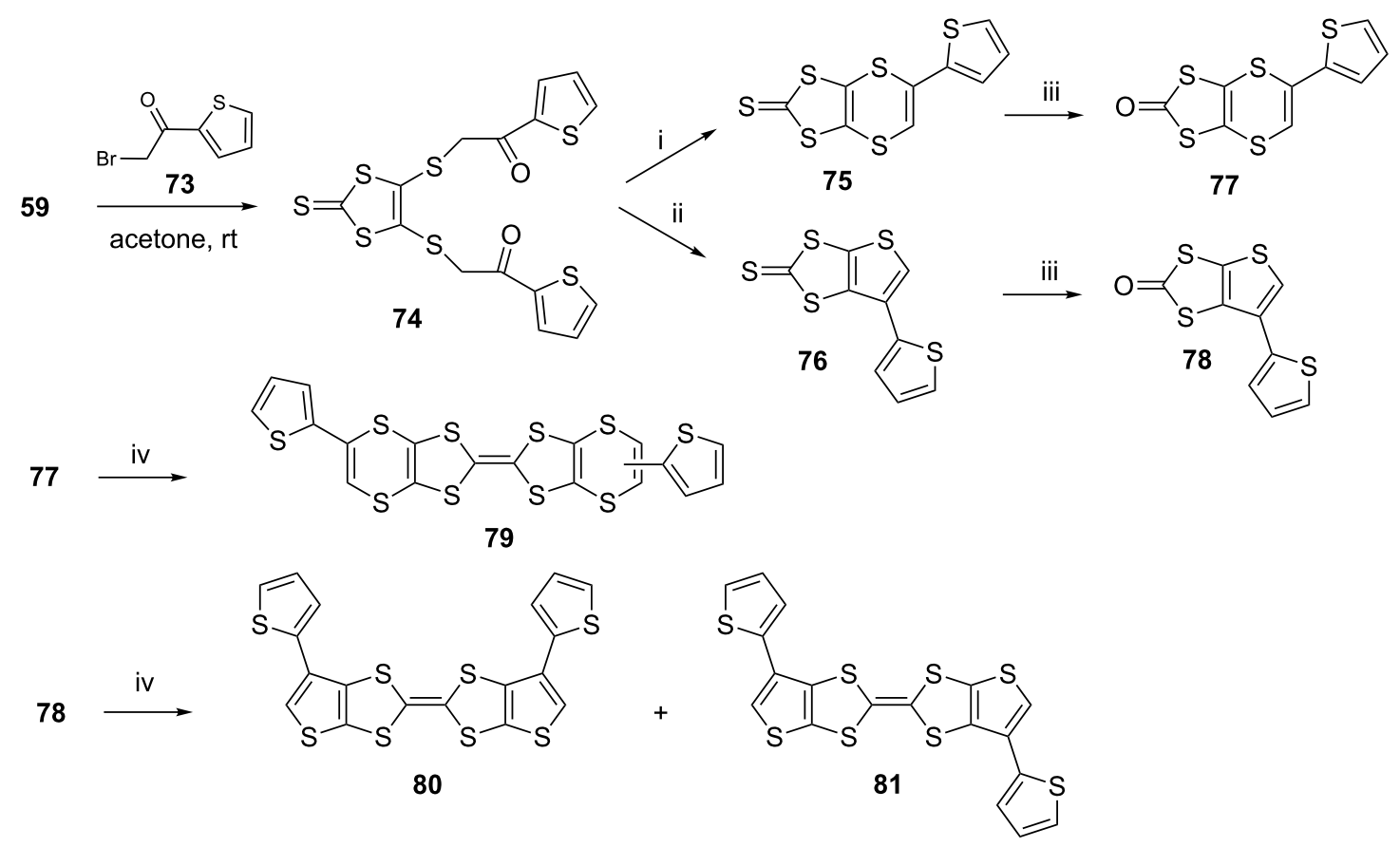

Scheme 11: Reaction and conditions (i) $\mathrm{P}_{4} \mathrm{~S}_{10}, \mathrm{NaHCO}_{3}$, toluene, reflux, $3 \mathrm{~h}$; (ii) $\mathrm{P}_{4} \mathrm{~S}_{10}, p$-TSA, toluene, reflux, $3 \mathrm{~h}$; (iii) $(\mathrm{AcO})_{2} \mathrm{Hg} / \mathrm{AcOH} \mathrm{CHCl}, 3 \mathrm{~h}$, rt; (iv) (EtO) ${ }_{3} \mathrm{P}, 110^{\circ} \mathrm{C}, \mathrm{N}_{2}, 2 \mathrm{~h}$.

Unfortunately, all attempts to electropolymerize the analogues failed. Computational studies indicated that the $\alpha$-carbons of the peripheral thiophenes, where the polymerization was expected to take place, did not exhibit enough spin density.

\section{Conclusion}

Bis(ethylenedithio)tetrathiafulvalene (BEDT-TTF, ET) is a unique molecule which has been successfully used as an electronic material that challenges the creativity and inventiveness of chemists in areas such as organic chemistry, materials chemistry, supramolecular chemistry and polymer chemistry. 1,8Diketones have been demonstrated to be versatile starting materials for the synthesis of various challenging analogues of ET, possessing dithiin and thiophene moieties. This chemistry not only led to the production of the target materials, having interesting electronic properties, but also illustrated challenging synthetic heterocyclic chemistry.

\section{Acknowledgements}

We thank Profesor John A. Joule of the University of Manchester for reading the manuscript, and Unsped Global Logistic for financial support.

\section{References}

1. Klingsberg, E. J. Am. Chem. Soc. 1964, 86, 5290-5292. doi:10.1021/ja01077a048
2. Wudl, F.; Smith, G.; Hufnagel, E. J. Chem. Soc. D 1970, 1453-1454. doi:10.1039/C29700001453

3. Wudl, F.; Wobschall, D.; Hufnagel, E. J. J. Am. Chem. Soc. 1972, 94, 670-672. doi:10.1021/ja00757a079

4. Ferraris, J.; Cowan, D.; Walatka, V. t.; Perlstein, J. J. Am. Chem. Soc. 1973, 95, 948-949. doi:10.1021/ja00784a066

5. Bryce, M. R. Chem. Soc. Rev. 1991, 20, 355-390. doi:10.1039/cs9912000355

6. Bryce, M. R. J. Mater. Chem. 2000, 10, 589-599. doi:10.1039/a908385e

7. Day, P.; Kurmoo, M. J. Mater. Chem. 1997, 7, 1291-1295. doi:10.1039/a608508c

8. Segura, J. L.; Martin, N. Angew. Chem., Int. Ed. 2001, 40, 1372-1409. doi:10.1002/1521-3773(20010417)40:8<1372::AID-ANIE1372>3.0.CO; 2-I

9. Jerome, D.; Mazaud, A.; Ribault, M.; Bechgaard, K. J. Phys., Lett. 1980, 41, 95-98. doi:10.1051/jphyslet:0198000410409500

10. Simonsen, K. B.; Svenstrup, N.; Lau, J.; Simonsen, O.; Mørk, P.; Kristensen, G. J.; Becher, J. Synthesis 1996, 407-418. doi:10.1055/s-1996-4216

11. Bryce, M. R. Adv. Mater. 1999, 11, 11-23. doi:10.1002/(SICI)1521-4095(199901)11:1<11::AID-ADMA11>3.0.CO; 2-3

12. Saito, G.; Yoshida, Y. Bull. Chem. Soc. Jpn. 2007, 80, 1-137. doi:10.1246/bcsj.80.1

13. Caneve, D.; Sallé, M.; Zhang, G.; Zhang, D.; Zhu, D. Chem. Commun. 2009, 2245-2269. doi:10.1039/b818607n

14. Tan, L.; Guo, Y.; Yang, Y.; Zhang, G.; Zhang, D.; Yu, G.; Xu, W.; Liu, Y. Chem. Sci. 2012, 3, 2530-2541. doi:10.1039/c2sc20303k

15. Akutsu, H.; Yamada, J.-i.; Nakatsuji, S.'i.; Turner, S. S. Dalton Trans. 2013, 42, 16351-16354. doi:10.1039/c3dt52346b 
16. Nielsen, M. B.; Lomholt, C.; Becher, J. Chem. Soc. Rev. 2000, 29, 153-164. doi:10.1039/a803992e

17. Garín, J.; Orduna, J.; Savirón, M.; Bryce, M. R.; Moore, A. J.; Morisson, V. Tetrahedron 1996, 52, 11063-11074. doi:10.1016/0040-4020(96)00624-2

18. Imakubo, T.; Okano, Y.; Sawa, H.; Kato, R. J. Chem. Soc., Chem. Commun. 1995, 2493-2494. doi:10.1039/c39950002493

19. Iyoda, M.; Hara, K.; Venkateswara Rao, C. R.; Kuwatani, Y.; Takimiya, K.; Morikami, A.; Aso, Y.; Otsubo, T. Tetrahedron Lett. 1999, 40, 5729-5730. doi:10.1016/S0040-4039(99)01085-0

20. Suzuki, T.; Yamochi, H.; Srdanov, G.; Hinkelmann, K.; Wudl, F. J. Am. Chem. Soc. 1989, 111, 3108-3109. doi:10.1021/ja00190a079

21. Kim, Y.-I.; Jeong, C.-K.; Lee, Y.-M.; Choi, S.-N. Bull. Korean Chem. Soc. 2002, 23, 1754-1758. doi:10.5012/bkcs.2002.23.12.1754

22. Jérome, D. Science 1991, 252, 1509-1514. doi:10.1126/science.252.5012.1509

23. Williams, J. M.; Schultz, A. J.; Geiser, U.; Carlson, K. D.; Kini, A. M.; Wang, H. H.; Kwok, W.-K.; Whangbo, M.-H.; Schirber, J. E. Science 1991, 252, 1501-1508. doi:10.1126/science.252.5012.1501

24. Kini, A. M.; Geiser, U.; Wang, H. H.; Carlson, K. D.; Williams, J. M.; Kwok, W.; Vandervoort, K. G.; Thompson, J. E.; Stupka, D. L. Inorg. Chem. 1990, 29, 2555-2557. doi:10.1021/ic00339a004

25. Abbaz, T.; Bendjeddou, A.; Gouasmia, A.; Villemin, D.; Shirahata, T. Int. J. Mol. Sci. 2014, 15, 4550-4564. doi:10.3390/ijms 15034550

26. Bendikov, M.; Wudl, F.; Perepichka, D. F. Chem. Rev. 2004, 104, 4891-4945. doi:10.1021/cr030666m

27. Nogami, T.; Inoue, K.; Nakamura, T.; Iwasaka, S.-I.; Nakano, H.; Mikawa, H. Synth. Met. 1987, 19, 539-544. doi:10.1016/0379-6779(87)90410-3

28. Lee, H.-J.; Kim, Y.-Y.; Noh, D.-Y. Bull. Korean Chem. Soc. 1998, 19 , 1011-1013.

29. Diaz, M. C.; Illescas, B. M.; Martin, N.; Viruela, R.; Viruela, P. M.; Orti, E.; Brede, O.; Zilbermann, I.; Guldi, D. M. Chem. - Eur. J. 2004, 10, 2067-2077. doi:10.1002/chem.200305555

30. Frère, P.; Skabara, P. J. Chem. Soc. Rev. 2005, 34, 69-98. doi:10.1039/b316392j

31. Santos, J.; Illescas, B. M.; Martín, N.; Adrio, J.; Carretero, J. C.; Viruela, R.; Ortí, E.; Spänig, F.; Guldi, D. M. Chem. - Eur. J. 2011, 17, 2957-2964. doi:10.1002/chem.201002674

32. Gao, X.; Wu, W.; Liu, Y.; Qiu, W.; Sun, X.; Yu, G.; Zhu, D. Chem. Commun. 2006, 2750-2752. doi:10.1039/b603632e

33. Yamochi, H.; Saito, G. Synth. Met. 1997, 85, 1467-1468. doi:10.1016/S0379-6779(96)04437-2

34. Rovira, C.; Veciana, J.; Santalo, N.; Tarres, J.; Cirujeda, J.; Molins, E.; Llorca, J.; Espinosa, E. J. Org. Chem. 1994, 59, 3307-3313. doi:10.1021/jo00091a017

35. Heuzé, K.; Fourmigué, M.; Batail, P.; Canadell, E.; AubanSenzier, P. Chem. - Eur. J. 1999, 5, 2971-2976.

doi:10.1002/(SICI)1521-3765(19991001)5:10<2971::AID-CHEM2971> 3.0.CO;2-S

36. Yamochi, H.; Komatsu, T.; Matsukawa, N.; Saito, G.; Mori, T.; Kusunoki, M.; Sakaguchi, K. J. Am. Chem. Soc. 1993, 115, 11319-11327. doi:10.1021/ja00077a034

37. Bryce, M. R. J. Mater. Chem. 1995, 5, 1481-1496. doi:10.1039/jm9950501481

38. Ikegawa, S.; Miyawaki, K.; Nogami, T.; Shirota, Y. Bull. Chem. Soc. Jpn. 1993, 66, 2770-2772. doi:10.1246/bcsj.66.2770
39. Wallis, J. D.; Griffiths, J.-P. J. Mater. Chem. 2005, 15, 347-365. doi:10.1039/b412561b

40. Ertas, E.; Ozturk, T. Chem. Commun. 2000, 2039-2040. doi:10.1039/b003714l

41. Nakamura, T.; Iwasaka, S.-i.; Nakano, H.; Inoue, K.; Nogami, T.; Mikawa, H. Bull. Chem. Soc. Jpn. 1987, 60, 365-368. doi:10.1246/bcsj.60.365

42. Kobayashi, H.; Kobayashi, A.; Sasaki, Y.; Saito, G.; Inokuchi, H. Bull. Chem. Soc. Jpn. 1986, 59, 301-302. doi:10.1246/bcsj.59.301

43. Jérome, D. Chem. Rev. 2004, 104, 5565-5592. doi:10.1021/cr030652g

44. Segura, J. L.; Martín, N. Angew. Chem., Int. Ed. 2001, 40, 1372-1409. doi:10.1002/1521-3773(20010417)40:8<1372::AID-ANIE1372>3.0.CO; 2-I

45. Yamada, J.-i.; Amano, Y.; Takasaki, S.; Nakanishi, R.; Matsumoto, K.; Satoki, S.; Anzai, H. J. Am. Chem. Soc. 1995, 117, 1149-1150. doi:10.1021/ja00108a040

46. Ozturk, T. Tetrahedron Lett. 1996, 37, 2821-2824. doi:10.1016/0040-4039(96)00396-6

47. Lebedev, V.; Laukhina, E.; Laukhin, V.; Rovira, C.; Veciana, J. Eur. J. Inorg. Chem. 2014, 24, 3927-3932. doi:10.1002/ejic.201402276

48. Pop, F.; Allain, M.; Auban-Senzier, P.; MartínezLillo, J.; Lloret, F.; Julve, M.; Canadell, E.; Avarvari, N. Eur. J. Inorg. Chem. 2014, 24 3855-3862. doi:10.1002/ejic.201400125

49. Zhang, B.; Zhang, Y.; Gao, Z.; Chang, G.; Su, S.; Wang, D.; Guo, Y.; Zhu, D. Eur. J. Inorg. Chem. 2014, 24, 4028-4032. doi:10.1002/ejic. 201402112

50. Ozturk, T.; Ertas, E.; Mert, O. Chem. Rev. 2007, 107, 5210-5278. doi:10.1021/cr040650b

51. Ozturk, T.; Ertas, E.; Mert, O. Chem. Rev. 2010, 110, 3419-3478. doi:10.1021/cr900243d

52. Svenstrup, N.; Becher, J. Synthesis 1995, 215-235. doi:10.1055/s-1995-3910

53. Turksoy, F.; Wallis, J. D.; Tunca, U.; Ozturk, T. Tetrahedron 2003, 59, 8107-8116. doi:10.1016/j.tet.2003.08.042

54. Ozturk, T.; Turksoy, F.; Ertas, E. Phosphorus, Sulfur Silicon Relat. Elem. 1999, 153, 417-418. doi:10.1080/10426509908546499

55. Horley, G. A.; Ozturk, T.; Turksoy, F.; Wallis, J. D. J. Chem. Soc., Perkin Trans. 1 1998, 3225-3232. doi:10.1039/a804779k

56. Atalay, Y.; Başoğlu, A.; Avcı, D.; Arslan, M.; Ozturk, T.; Ertas, E. Physica B 2008, 403, 1983-1989. doi:10.1016/j.physb.2007.11.002

57. Ertas, E.; Betul Kaynak, F.; Ozbey, S.; Osken, I.; Ozturk, T. Tetrahedron 2008, 64, 10581-10589. doi:10.1016/j.tet.2008.08.085

58. Ertas, E.; Bildirir, H.; Sahin, O.; Oksen, I. Phosphorus, Sulfur Silicon Relat. Elem. 2013, 188, 1835-1844. doi:10.1080/10426507.2013.788005 


\section{License and Terms}

This is an Open Access article under the terms of the Creative Commons Attribution License

(http://creativecommons.org/licenses/by/2.0), which permits unrestricted use, distribution, and reproduction in any medium, provided the original work is properly cited.

The license is subject to the Beilstein Journal of Organic Chemistry terms and conditions:

(http://www.beilstein-journals.org/bjoc)

The definitive version of this article is the electronic one which can be found at:

doi:10.3762/bjoc. 11.46 